\title{
Industrijsko nasleđe u Vojvodini: zaštita, tipologija i moguća revitalizacija danas
}

\author{
Vladimir Stojanović \\ Univerzitet u Novom Sadu, Prirodno-matematički fakultet, Departman za \\ geografiju, turizam i hotelijerstvo, Srbija \\ e-mail:vladimir.stojanovic@dgt.uns.ac.rs
}

\section{Bogdan Janjušević \\ Pokrajinski zavod za zaštitu spomenika kulture Petrovaradin, Srbija e-mail: bogdan.janjusevic@pzzzsk.rs}

\begin{abstract}
SAŽETAK U proteklih nekoliko decenija teme o industrijskom nasleđu su relativno često prisutne u praktičnim i naučnim raspravama. One su relativno široke i kreću se u rasponu od identifikacije, preko zaštite i obnove, do održivog korišćenja. S obzirom na bogatu industrijsku prošlost, Vojvodina je višestruko značajna kako u Srbiji, tako i šire, za proučavanje industrijskog nasleđa. Ovaj rad se, nakon kraćeg istorijskog osvrta na industrijski razvoj u Pokrajini, bavi mogućnostima primene aktuelnih tipologija industrijskog nasleđa, kao i temama o njegovoj zaštiti. Pitanja zaštite bi trebalo potražiti i u održivim vidovima korišćenja objekata industrijskog nasleđa, u situaciji kada njihova primarna funkcija nije aktuelna i kada novi vidovi neadekvatnog korišćenja prete da izbrišu materijalne tragove ovog važnog dokaza industrijalizacije u Vojvodini.
\end{abstract}

Ključne reči: industrijsko nasleđe, deindustrijalizacija, Vojvodina, tipologija, zaštita, revitalizacija, održivi razvoj.

\section{Uvod}

Koreni procesa industrijalizacije u Vojvodini sežu do druge polovine 18. stoleća, u vreme Habsburške monarhije, kada je poljoprivreda na teritoriji današnje Pokrajine bila osnova za razvoj austrijske industrije i kada su ovde počele da se otvaraju prve manufakture za preradu poljoprivrednih proizvoda (Mirnić, 1963.). Proces industrijalizacije je nastavljen u 19. i potom u 20. stoleću. Iz tog perioda datiraju brojna industrijska postrojenja koja se, tek sa počecima deindustrijalizacije, nakon raspada Jugoslavije, analiziraju u kontekstu zaštite nasleđa. Ovde se postavljaju i neke važne dileme - koliko su ti objekti vredni, koliko može biti korisna njihova zaštita, gde je mesto industrijske baštine u planovima održivog razvoja. 
U skladu sa prethodno navedenim, osnovna istraživačka pitanja u ovom radu se odnose na: (1) analizu mogućnosti zaštite industrijskog nasleđa Vojvodine, pre svega kroz prizmu zakonodavstva; (2) tipologiju nasleđa, što je pokušaj uvođenja sistematičnosti u njegovom proučavanju i korišćenju i (3) prezentaciju onih vidova održivog korišćenja industrijskog nasleđa koji bi se mogli primeniti i u slučaju industrijskog nasleđa Vojvodine.

Definicije industrijskog nasleđa, od samih početaka proučavanja ove oblasti, insistiraju na širokom pristupu, kao i na odbacivanju rigidnih granica u određenju ovog segmenta baštine (Hudson, 1963.). Industrijsko nasleđe obuhvata fragmente industrijske kulture koji imaju istorijsku, tehničku, društvenu, arhitektonsku ili naučnu vrednost. Industrijsko nasleđe čini najraznovrsnija materijalna i nematerijalna zaostavština: objekti, mašine, radionice, mlinovi, fabrike, rudnici, skladišta, prodavnice, mesta za proizvodnju i prenos energije, saobraćajna infrastruktura, radničke kolonije i nematerijalno nasleđe (The Nizhny Tagil Charter for the Industrial Heritage, 2003.).

Razumevanje industrijskog nasleđa povezano je sa procesima industrijalizacije i deindustrijalizacije. Industrijalizacija je proces u kome industrijska delatnost ima dominantnu ulogu u ekonomiji neke nacije ili regije, spontano ili kao rezultat planiranja (Smith, 2001.). Deindustrijalizacija je neprekidno opadanje industrijske aktivnosti i kapaciteta, uključujući i nivo zaposlenosti (Lee, 2001.). U centru i jednog i drugog procesa nalazi se pojam industrijskog predela, neophodan za razumevanje šireg konteksta u proučavanju industrijskog nasleđa. Koncept industrijskog predela koristi se da opiše i klasifikuje zaostavštinu materijalne industrijske kulture, kako bi joj se pripisalo novo značenje, sa ciljem stvaranja teorijske osnove i praktične metodologije za nove proizvodne sisteme i kulturno korišćenje (Loures, 2008.). Vojvodina je u prethodnih 200 godina prošla i kroz jedan i kroz drugi proces, a kao posledica toga, u Pokrajini su i danas uočljivi brojni industrijski predeli.

Brojni autori proučavaju industrijsko nasleđe i njegov značaj. Zbog njegove arhitektonske, društvene, istorijske i tehnološke vrednosti, ono može biti važan faktor u formiranju kulturnog identiteta. Isto tako, ono može biti snažan faktor u urbanoj regeneraciji (Cizler, 2012.). Lokacije napuštenih industrijskih objekata obično se nalaze na obodima centralnih zona gradova, pa su iz tog razloga one podesne za projekte koji za posledicu imaju značajne socijalne efekte. Takođe, prisutan je i javni interes, oličen u težnji stanovništva, da se zaštiti postojeća slika mesta i tako odbrani identitet okruženja (Mihajlov, 2009.).

Čak i u oceni da je u poslednjih nekoliko godina ostvaren pomak u „spontanom“ prepoznavanju potencijala industrijskog nasleđa, činjenica je da industrijsko nasleđe u Vojvodini nije dovoljno proučeno, zaštićeno i u funkciji održivog razvoja. Situacija na terenu ide u prilog ubrzanom nestajanju velikog broja objekata industrijskog nasleđa. U većim gradovima (npr. Novi Sad) već je porušen jedan deo nasleđa radi izgradnje stambeno-poslovnih kompleksa na atraktivnim lokacijama. Za razliku od većih gradova, u manjim sredinama su ove zgrade često napuštene i prepuštene propadanju. 


\section{Pregled dosadašnjih inicijativa, istraživanja i literature o zaštiti, tipologiji i održivom korišćenju industrijskog nasleđa u svetu}

Teme u vezi sa zaštitom industrijskog nasleđa se počinju pojavljivati u međunarodnim dokumentima i poveljama osamdesetih godina 20. stoleća. Preporuku o zaštiti i konzervaciji industrijskog, tehničkog i građevinskog nasleđa u Evropi usvojio je Savet Evrope 1990. godine (Recommendation No. R (90) 20. of the Committee of Ministers to member state on the protection and conservation of the Industrial, technical and civil engineering heritage in Europe, 1990.). Na Generalnoj skupštini Međunarodnog saveta za spomenike i spomeničke celine (International Council on Monuments and Sites - ICOMOS) 2011. usvojeni su „Dablinski principi“ u kojima se između ostalog daju najaktuelnije definicije industrijskog nasleđa, uključujući pojedinačne objekte, celine i urbane predele. Ovde se ističe da je neophodno osigurati delotvornu zaštitu i očuvanje struktura industrijskog nasleđa, lokacija, područja i predela. Na putu do tog cilja neophodno je razviti i koristiti integrisani popis objekata i predela industrijskog nasleđa (uključujući dokumente, crteže i arhive). Neophodno je zakonsko prepoznavanje, adekvatna zaštita i upravljanje, kako bi se obezbedilo očuvanje tih objekata i predela (Joint ICOMOS - TICCIH Principles for the Conservation of Industrial Heritage Sites, Structures, Areas and Landscapes - The Dublin Principles, 2011.).

Tipologiju industrijskog nasleđa prepoznaje više inicijativa i konkretnih dokumenata. Industrijsko nasleđe u Evropi može se klasifikovati u nekoliko kategorija. Ako se uzme u obzir namena za koju su pojedini objekti podignuti, onda se oni mogu svrstati u sledeće tipove: (1) objekti namenjeni industrijskoj proizvodnji, (2) objekti namenjeni proizvodnji energije, (3) objekti hidrotehničkog karaktera, (4) objekti transportne infrastrukture (Fetisov, 2013.).

Nešto složenija tipologija data je jednoj u američkoj klasifikaciji, odnosno, prema „Istorijskom američkom inženjerskom registru“ koji navodi deset kategorija industrijskog nasleđa:

1. rudarska industrija (podzemni i površinski kopovi, solane);

2. industrija „rasutih“ proizvoda (poljoprivredna proizvodnja, topionice, hemijska industrija, prehrambena industrija, metalska industrija, tekstilna i drvna industrija);

3. prerađivačka industrija (proizvodnja mašina, transportnih sredstava, finalnih metalnih proizvoda, industrija oružja, finalna obrada drveta i drugih materijala, precizna mehanika i drugo);

4. komunalna infrastruktura (vodovod i kanalizacija, snabdevanje gasom i električnom energijom);

5. proizvodnja energije (vodene turbine, parne turbine);

6. transport (železnice, putevi, kanalska mreža i navigacija, luke, lukobrani, dokovi, obalski nasipi, svetionici, brodovi, aerodromi i letelice, naftovodi i gasovodi);

7. komunikacije (telefon i telegraf, radio i televizija);

8. mostovi, stubovi i akvedukti;

9. tehnologije gradnje (temelji, skeletne konstrukcije, međuspratne konstrukcije, krovne konstrukcije i drugo); 
10. specijalizovane strukture i objekti (brane, tuneli, hidraulične prevodnice, kanali, navodnjavanje, fabrički dimnjaci, peći, rashladna postrojenja, magacini i drugi skladišni prostor, radničko stanovanje, muzeji tehnike) (Falser, 2001.).

Pored ovih osnovnih tipologija, koje mogu imati varijacije u zavisnosti od karakteristika lokalnog nasleđa na koje se istraživanje odnosi, mogu se razviti i složenije tipologije koje se odnose na uske specifičnosti pojedinih objekata ili postrojenja. Tipologija industrijskih objekata može biti izvedena na osnovu specijalizovane namene zgrada, na primer, proizvodne, pomoćne, energetske industrijske zgrade, zgrade u funkciji transporta, magacini i druge zgrade za skladištenje. Prema svojoj nameni mogu se dalje deliti i proizvodne zgrade, na primer, mašinska, građevinska industrija, upravne zgrade, magacini i slično (Fetisov, 2013.).

Osim prethodno pomenutih tipologija ističe se i fotografska tipologija industrijskih objekata koju su tokom četiri decenije svog fotografskog, umetničkog i istraživačkog rada razvijali Bernd i Hila Beher (Becher i Becher, 2004.). Njihove fotografije predstavljaju konceptualnu umetnost, tipološku studiju i topografsku dokumentaciju. Oslanjajući se na tradiciju nemačkih majstora fotografije iz dvadesetih godina 20. veka, oni su se posvetili fotografskom dokumentovanju industrijske arheologije, istovremeno stvarajući i tipološku studiju industrijskog nasleđa.

Najzad, analiza održivog korišćenja industrijskog nasleđa se posmatra kao pitanje održivog razvoja gradova (Sýkora et al, 2010.) i regija, a veoma često je posmatrana i kroz konkretne studije slučaja, na primer, Idrija u Sloveniji. U ovoj destinaciji se potencira povezanost prirodnog i tehnološkog razvoja, uočljiva posebno u razvoju rudarstva tokom prethodnih 500 godina. Nakon gašenja rudarstva šansa privrednog razvoja je otkrivena u turizmu, koji se zasniva na zaštiti rudarskog nasleđa, a počiva i na edukaciji o povezanosti ljudi i prirode. Zaštita industrijskog nasleđa ovde se vidi kao dužnost lokalnih autoriteta (Gorjup-Kavčič et al, 2010.).

Koncepcija održivog razvoja je postala opšteprisutna u globalnoj debati, a različiti akteri koriste ovaj pojam da bi izrazili različite vizije za privredu, životnu sredinu i društvo. Svima je zajedničko to što se ističe razvoj koji zadovoljava potrebe sadašnjih generacija, bez mogućnosti ugrožavanja zadovoljavanja potreba budućih generacija (Adams, 2009.). Održivi razvoj objekata industrijskog nasleđa se posmatra kao katalizator prostorno i društveno širih promena, koje uključuju i analizu potreba zajednica lokalnog stanovništva. Ovde je akcenat na ponovnoj upotrebi industrijskih postrojenja, što pruža šansu za uključivanje lokalnog stanovništva u procese rekonstrukcije industrijskog nasleđa. Takva rekonstrukcija u poslednjih nekoliko decenija uvažava karakter i integritet tih objekata (Industrial Heritage in Europe, 2013.). U sadejstvu sa ekonomskim pitanjima i investicijama, industrijsko nasleđe se veoma često vidi kao resurs za razvoj turizma. Turizam industrijskog nasleđa se bazira na: (1) obilasku industrijskih muzeja, eksterijera i predela; (2) poštovanju estetskih vrednosti arhitekture i artefakata i (3) uživanju u nematerijalnoj baštini kroz učestvovanje u kulturnim događajima koji su zasnovani na industrijskoj tradiciji (Feifan Xie, 2015.). 


\section{Razvoj industrije u Vojvodini kao istorijski uslov postanka industrijskog nasleđa}

Nakon potiskivanja Turaka, sa područja današnje Vojvodine, na istorijsku pozornicu je stupio prosvećeni apsolutizam Marije Terezije, paralelno sa formiranjem Vojne granice i brojnim kolonizacijama. Etnički dominantni među doseljenicima bili su Nemci. Njihove kolonizacije su realizovane u više navrata tokom 18. veka (Kicošev i saradnici, 2006.). Kolonizacije su bile od presudnog značaja za formiranje specifičnog društvenog okvira u kome će se razvijati područje današnje Vojvodine u predstojećim stolećima. Pored toga, razvoj Ugarske je vidno zavisio od Austrije, što se odrazilo na vid i stepen privrednog razvoja. Na primer, privredni razvoj Bačke tokom 18. veka u tesnoj je vezi sa interesima tadašnje Austrije. Još 1768. Marija Terezija upućuje pitanje Ekonomskom savetu o mogućnostima privrednog unapređivanja ovih krajeva. Savet preporučuje da se oni pretvore u centre za proizvodnju sirovina i poluproizvoda (lana, konoplje, svile, vune), uz paralelno razvijanje domaće radinosti. To je uticalo na stvaranje razgranate mreže manjih privrednih centara kao što su: Apatin, Odžaci, Senta, Bečej, Bačka Palanka, Buljkes, Bezdan, Crvenka i Sivac (Mirnić, 1963.).

Ugarska privreda tog vremena je bila pod snažnim uticajem Bečkog dvora, i to u politici koja se zasnivala na principu unapređenja austrijske privrede, dok je Ugarska dobila ulogu liferanta poljoprivrednih proizvoda. Oslanjanje na poljoprivredu dovelo je do razvoja sledećih industrijskih grana: (1) mlinske industrije (Novi Sad, Nova Palanka, Senta, Sombor, Crvenka, Subotica, Kikinda); (2) industrije šećera (Novi Vrbas, Crvenka, Zrenjanin); pivarske industrije (Bečej, Apatin, Čelarevo, Zrenjanin, Pančevo, Sremska Mitrovica); (3) industrije za preradu kudelje (Odžaci, Apatin, Novi Vrbas, Čelarevo, Novi Futog, Novi Sad, Torža). (Mezei, 1959.).

Ipak, pogrešno je smatrati da je celokupni industrijski razvoj Ugarske, pa tako i Vojvodine, zavisio samo od poljoprivrede. Izgradnja Velikog Bačkog kanala krajem 18. i početkom 19. veka predstavljala je u tadašnjoj Evropi jedan od najvećih hidrotehničkih projekata, usmeren na isušivanje vodoplavnih zemljišta i stvaranje unutrašnjih plovnih puteva. Prvobitno kanal je povezivao Dunav kod Bačkog Monoštora i Tisu kod Bačkog Gradišta. Zbog pomeranja korita Dunava sredinom 19. stoleća vodozahvat je izmešten kod Bezdana (slika 1), dok je krajem istog stoleća zbog regulacionih radova na Tisi, „ušće“ kanala izmešteno kod Bečeja (Milošev, 2002.). Izgradnja kanala je kasnije bila podsticaj za podizanje drugih industrijskih objekata, na primer mlinova, od kojih je onaj u Malom Staparu do danas očuvan i predstavlja reprezentativan objekat industrijske baštine. 
Slika 1.

Početak Velikog Bačkog kanala kod Bezdana, sa prevodnicom iz 1856. godine - prvim betonskim objektom ovakve vrste u Evropi

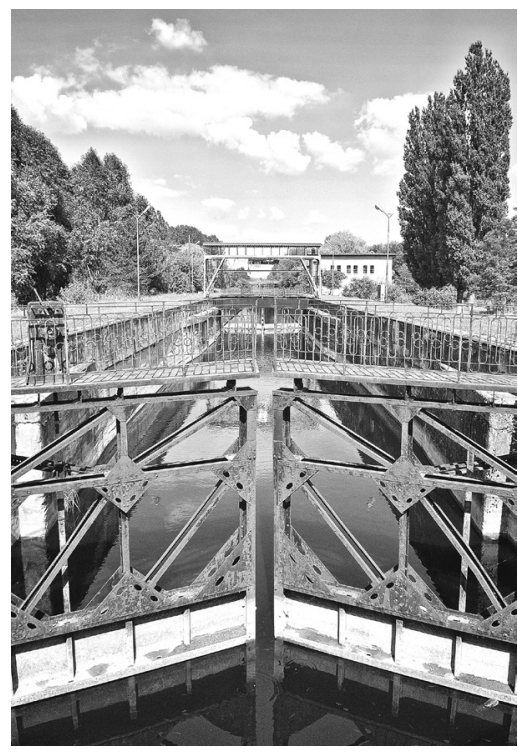

Foto: Lazar Lazic

Na osnovu istorijskih izvora moguće je zaključiti da je lokacija industrije na području današnje Vojvodine inicirana dvema grupama faktora lokacije: (1) faktori prirodne sredine i (2) društveni faktori (socio-ekonomski faktori). Mada faktori prirodne sredine nemaju tako veliki značaj za lokaciju savremenih industrijskih objekata, ispostavlja se da u istorijskom tumačenju njihov značaj za lokaciju industrije Vojvodine jeste velik. Samo je u povoljnim uslovima za poljoprivrednu proizvodnju bilo moguće razvijati privredne grane koje su obezbeđivale sirovinsku bazu za austrijsku industriju, u koju su spadale i sledeće poljoprivredne kulture: konoplja, lan, svilena buba, pa čak i pirinač (npr. Peklapusta u Bačkoj).

\section{Pristup zaštiti industrijskog nasleđa u Vojvodini}

Zakonodavstvo u Srbiji ne prepoznaje industrijsko nasleđe kao posebnu vrstu kulturnog dobra već se ono može zakonski štititi kao spomenik kulture ili prostorna kulturno-istorijska celina na osnovu aktuelnog Zakona o kulturnim dobrima (Službeni glasnik RS, br. 71/94.). To je osnovni zakon koji reguliše oblast zaštite kulturnih dobara u Republici Srbiji i ovim zakonom uređuje se sistem zaštite i korišćenja kulturnih dobara i utvrđuju uslovi za obavljanje delatnosti zaštite kulturnih dobara. Manji broj objekata industrijskog nasleđa uživa status nepokretnog kutlurnog dobra. Među njima su: Kompleks crpne stanice „Kučka“ i stari pogon fabrike čarapa „Vukica Mitrović“ u Apatinu, Kudeljara (Mljač) u Bačkom Petrovcu, Prevodnica „Šlajz“ u Bečeju“ (kategorisana kao kulturno dobro od izuzetnog značaja) i drugi. U evi- 
denciji nadležnih zavoda za zaštitu spomenika kulture nalazi se veći broj objekata industrijskog nasleđa koji zbog komplikovane i dugotrajne procedure još uvek ne uživaju zakonsku zaštitu.

Valorizacija industrijskog nasleđa se može izvršiti na nekoliko različitih nivoa: (1) istorijski nivo - ističe svedočanstvo o epohi industrijalizacije, koja je kako u svetu, tako i u Vojvodini, donela modernizaciju, urbanizaciju i savremeno doba (izgradnja fabričkih zgrada, stambenih naselja, javnih ustanova); (2) tehnološki nivo - oličen u očuvanju mašina i postrojenja, koja su svojevremeno predstavljala revolucionarne pronalaske; (3) arhitektonski nivo - ogleda se u primeni novih građevinskih materijala i konstruktivnih sistema, koji su veoma značajni za lokalno graditeljsko nasleđe; (4) društveni nivo - najkompleksniji je za razumevanje, jer naglašava pitanje identifikovanja sa nasleđem i krizu identiteta nakon deindustrijalizacije (Cizler, 2016.).

Slika 2.

Fabrika kanapa i užarije u Odžacima, koja je bitno promenila lokalnu istoriju ovog mesta (razglednica s početka 20. stoleća)

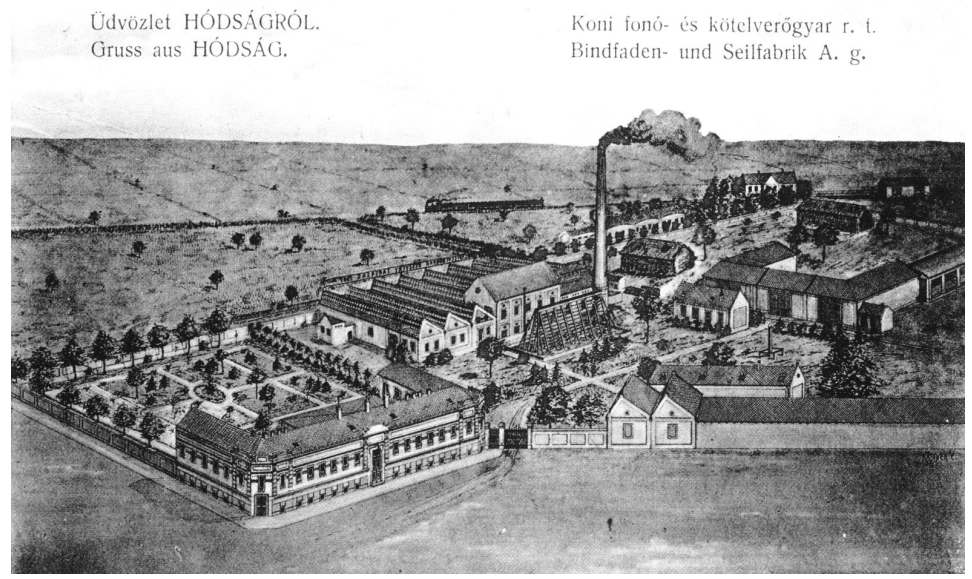

Izvor: Preslika stare razglednice

Svaki od pomenutih nivoa jeste ili može biti prisutan u valorizaciji industrijskog nasleđa Vojvodine i svaki od njih je nesumnjivo važan u zaštiti tog nasleđa. Razvoj industrije je uticao na promenu ekonomske istorije u Vojvodini. U regiji koja je prirodno predodređena za razvoj poljoprivrede, doneo je industriju koja je bitno povezana sa urbanizacijom. O tome svedoče i mnoga istraživanja (Mezei, 1959.). Međutim, isto tako je zanimljivo da lokaliteti industrijskog nasleđa mogu isticati istoriju koja je izostala u udžbenicima ili poznatijim knjigama. Takva istorija „marginalnog“ predstavlja život ljudi na način koji je provokativan i zanimljiv širem auditorijumu (Johnson, 2009.). Iz toga sledi da je zaštita objekata industrijskog nasleđa istovremeno i zaštita manje poznatih istorijskih događaja od zaborava. Kao primer može poslužiti porodica Ertl u čijem je vlasništvu bila Fabrika kanapa i užarije u Odžacima (slika 2). Oni su značajano unapredili sredinu u kojoj su živeli kroz podizanje radničkih kolonija, sportskih terena, javnih ustanova. Konačno, fabrika koju su osnovali nakon Drugog 
svetskog rata je zapošljavala 2.500 radnika (Stojanović, 2007.). Industrijalizacija je, posebno na prelazu 19. u 20. vek, uticala na uvoz mašina i opreme za industrijsku proizvodnju, kao značajnih tehničko-tehnoloških inovacija tog vremena. Mnoge od njih još uvek nisu evidentirane, a mnoge su trajno izgubljene u gašenju i privatizaciji fabrika u protekle dve decenije. Dalje, zaštitom industrijske baštine, takođe se čuva i arhitektonska baština u Vojvodini. Arhitekturu industrijskih objekata karakteriše svedena dekorativnost, uravnotežene proporcije i ritmičnost prozorskih okvira i krovnih masa. Zahvaljujući postignutom skladu arhitektonskih elemenata, mnogi industrijski objekti u Vojvodini spadaju među veoma značajne primere graditeljskog nasleđa. Neki od vrednijih objekata su u stilu secesije, kao na primer oni sagrađeni prema projektu Lasla Sekeljija (László Székely), priznatog arhitekte iz Temišvara (Karavida, 2014.).

\section{Mogućnost primene aktuelnih tipologija industrijskog nasleđa u Vojvodini}

U ovom istraživanju biće izvedena osnovna tipologija industrijskog nasleđa u Vojvodini, zasnovana na nameni većih grupa objekata, kompleksa ili infrastrukture i bazirana na tipologiji karakterističnoj za evropske gradove. Takođe, ona će biti prilagođena lokalnom istorijskom razvoju. Za izvođenje kompleksnije tipologije industrijskog nasleđa u Vojvodini, po prethodno navedenim specifičnim parametrima i usklađeno sa američkom tipologijom (HAER - Historic American Engineering Record), neophodna su obimna istraživanja, za koja do sada nisu stečeni odgovarajući uslovi.

Uzimajući u obzir funkciju industrijskih objekata, a na osnovu izvršenih istraživanja za potrebe ovog rada, mogu se izvesti sledeći osnovni tipovi industrijskog nasleđa:

1. Objekti industrijske proizvodnje:

1a. prerada poljoprivrednih proizvoda i prehrambena industrija,

1b. industrija građevinskog materijala,

1c. tekstilna industrija i prerada sirovina za tekstilnu industriju,

1d. industrija finalnih proizvoda i ostali industrijski pogoni;

2. Industrijski objekti za proizvodnju energije;

3. Objekti radničkog stanovanja;

4. Hidrotehničko nasleđe;

5. Objekti transportne infrastrukture.

\subsection{Objekti industrijske proizvodnje}

Kao prvi tip industrijskog nasleđa izdvajaju se objekti namenjeni industrijskoj proizvodnji. U okviru ovog tipa može se izdvojiti nekoliko podtipova kojima bi se definisala vrsta proizvodnje koja se u ovim objektima odvijala.

Prvi podtip predstavlja prerada poljoprivrednih proizvoda i prehrambena industrija. Industrijski razvoj Vojvodine usko je povezan sa industrijskom revolucijom 
u Mađarskoj koja se zapravo odvijala osamdesetih godina 19. veka (Karavida, 2016. a). Fabrička prerada žitarica i mesa, i proizvodnja šećera, obeležila je ovaj period privrednog razvoja. U Vojvodini se industrijska proizvodnja, slično kao i na teritoriji cele tadašnje Ugarske, bazirala pre svega na preradi poljoprivrednih proizvoda i proizvodnji hrane i pića (mlinovi, klanice, pivare, šećerane i sl.). Mlinska industrija je bila najzastupljenija širom Bačke, Banata i Srema. U urbanističkom, arhitektonskom i tehnološkom smislu mogu izdvojiti tri vrste kompleksa: pivare, šećerane i klanice (Karavida, 2016. a,b).

Začeci pivarske industrije mogu se pronaći još početkom 18. veka. Prva vojvođanska pivara je osnovana 1722. u Pančevu. Apatinska pivara je sagrađena 1756. godine po tadašnjim evropskim standardima (slika 3). Za razliku od drugih pivara, gradi je Carska komora. Po arhitekturi fabričkih zgrada, tehnologiji i proizvodnim kapacitetima, već tada je odgovarala parametrima industrijskog preduzeća (Karavida, 2016. a). Industrijska proizvodnja piva postojala je i u Pančevu, Bečeju (osnovana 1754.), Zrenjaninu (osnovana 1745., modernizovana 1891.-1911.) (slika 4), Vršcu (osnovana 1742.) i Čelarevu (sagradio Lazar Dunđerski 1891.) (Tufegdžić, 2014.). Industrija šećera se razvija početkom 20. veka kada počinje sistematski uzgoj šećerne repe zahvaljujući državnoj poljoprivrednoj politici. Prve izgrađene šećerane bile su u Velikom Bečkereku (1910.), Crvenki (1911.) i Vrbasu (1912.). Građene su van naseljenih mesta sa zgradama paviljonskog tipa. U okviru kompleksa su građene i administrativne zgrade kao i zgrade za stanovanje među kojima su se razlikovale vile za rukovodeći kadar, stanovi za činovnike i stanovi za radnike (Karavida, 2014.; Karavida, 2016. a; Vrbaški, 2009.).

Slika 3.

Zgrade u sastavu Apatinske pivare (prvi put sagrađena 1756. godine)

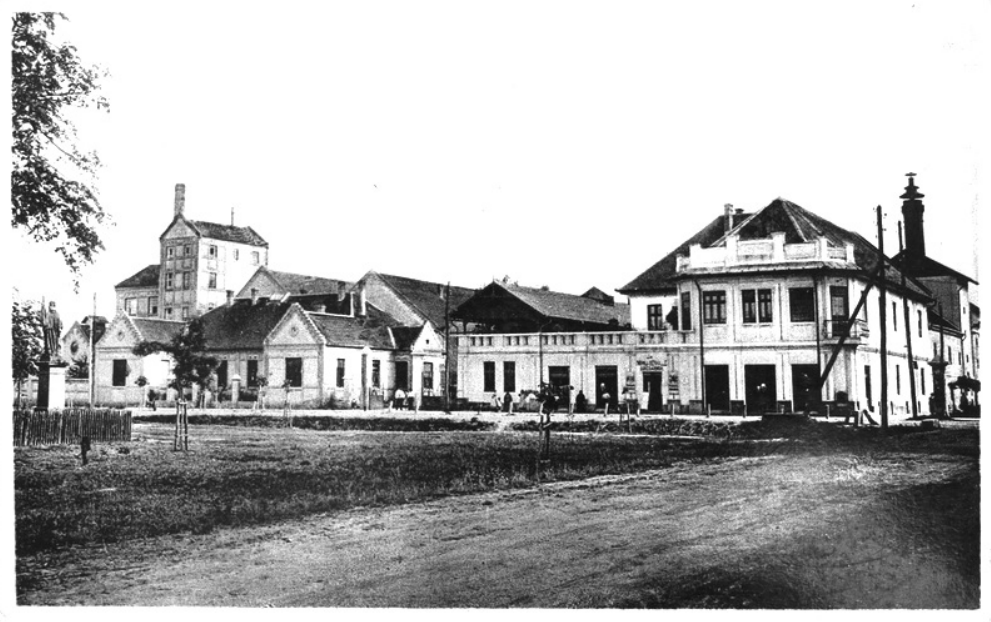


Slika 4.

Zgrade u sastavu Zrenjaninske pivare na obali Begeja

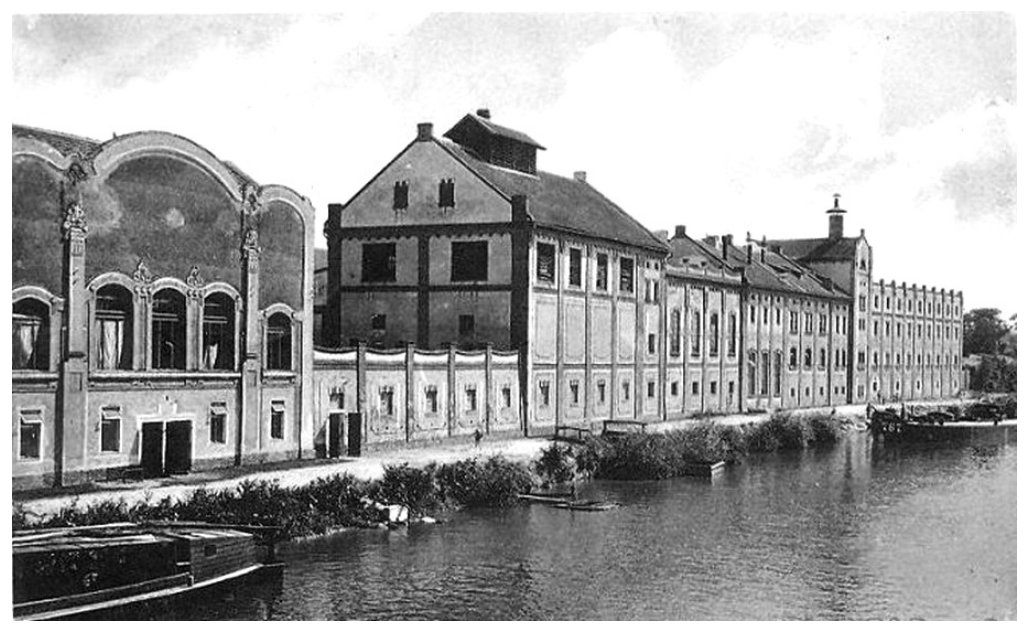

Izvor: Zavod za zaštitu spomenika kulture Zrenjanin

Početkom 20. veka u Vojvodini se grade savremene klanice koje su morale da zadovolje stroge zakonske akte po pitanju higijene i tehničkih standarda. Stručnjak koji se specijalizovao za objekte ove vrste bio je Laslo Sekelji, gradski arhitekta iz Temišvara. Po njegovim projektima izgrađene su klanice u Temišvaru, Velikom Bečkereku, Somboru i Pančevu, sve u periodu između 1904. i 1914. godine (Karavida, 2014.).

Drugi podtip predstavlja industrija građevinskog materijala (ciglane, cementare). Tokom 19. veka proizvodnja cigle prelazi u manufakturnu, a zatim u industrijsku proizvodnju. Nakon uvođenja Hofmanove kružne peći započinje industrijska proizvodnja keramičkih proizvoda. U Vojvodini je postojao veliki broj ciglana od kojih su do danas sačuvane ciglana Ferenca Rajhla u Subotici, ciglane u Bačkoj Topoli, Plavni, Uzdinu, Kovinu, Debeljači, Stanišiću i drugim mestima (Vujović, 2016.).

Pored opeke proizvodio se i crep (prvobitno samo biber crep), a nešto kasnije i keramički proizvodi (fabrika „Polet“ u Novom Bečeju iz 1907.) (Vujović, 2016.).

Proizvodnja cementa je započela sredinom 19. veka u Beočinu gde je eksploatisan laporac kao osnovna sirovina. Zahvaljujući ovoj činjenici u Beočinu nastaje veliki industrijski kompleks i tri tipske kolonije građene za smeštaj radnika i njihovih porodica. Jedan broj zgrada korišćenih u procesu proizvodnje sačuvan je do danas, kao i nekoliko upravnih zgrada. Jedan od najznačajnijih objekata do danas sačuvanih u krugu fabrike je vodotoranj iz 1896. godine, sagrađen od armiranog betona (Janjušević, 2015.).

Treći podtip je predstavljala tekstilna industrija i prerada sirovina za tekstilnu industriju čiji koreni datiraju još iz 18. veka. U Vojvodini se grade kudeljare, svilare 
i tkačnice, najčešce u blizini izvora sirovina radi jednostavnijeg i jeftinijeg procesa transporta i proizvodnje. Konoplju donose kolonisti sredinom 18. veka, mada je ovde i od ranije poznata. Najznačajnija fabrika za preradu kudeljnog vlakna na ovim prostorima bila je Ertlova fabrika u Odžacima, osnovana 1907. godine (Stojanović, 2007.). Svilarstvo je bilo podsticano državnom politikom još od 1751. godine, a izgradnja svilara i pratećih objekata intenzivirana je u periodu od 1880. do prvih godina 20. veka (Vujović, 2016.). Tkačko zanatstvo i oprema za rad dolazi krajem 19. veka iz Mađarske i Češke. Najpoznatija tkačnica, u Bezdanu, poseduje razboje iz 1871. godine (Vujović, 2016.).

Četvrti podtip čine industrija finalnih proizvoda i ostali industrijski pogoni. Pored navedenih podtipova, među objektima industrijske proizvodnje u Vojvodini je tokom prve polovine 20. veka funkcionisalo više fabrika finalnih proizvoda. U Zrenjaninu je još sredinom 19. veka osnovana fabrika nameštaja „Bence“, a početkom 20. veka fabrika tepiha „Dunđerski“. Fabrika metalnog nameštaja postojala je i u Subotici. Nakon završetka Prvog svetskog rata i ujedinjenja sa Srbijom, Pančevo postaje sve značajniji industrijski centar zbog blizine nove prestonice. Ovde je 1929. godine počela sa radom „Prva pančevačka parna stolarija i strugara“, 1931. fabrika sijalica „Tesla“, 1932. fabrika stakla, zatim livnica u Kačarevu, fabrika dugmadi u Ivanovu, nekoliko štamparija i „Utva“ u Pančevu koja je osnovana 1940. godine (Vujović, 2016.). U Novom Sadu je 1923. godine osnovana fabrika aviona „Ikarus“, koja je kasnije preseljena u Zemun.

\subsection{Industrijski objekti za proizvodnju energije}

Kao poseban tip izdvajaju se industrijski objekti za proizvodnju energije (termocentrale, hidrocentrale), odnosno, električne energije. Ovaj tip objekata u Vojvodini se pojavljuje krajem 19. i početkom 20. veka kada se grade i prve električne centrale (električna centrala u Subotici puštena je u pogon 1896., Somboru 1903., a Novom Sadu 1910. godine). Pored termoelektrana, koje su proizvodile najveći deo električne energije, postojala je i proizvodnja struje na hidrotehničkim objektima (prevodnica na Malom Staparu, za lokalne potrebe).

\subsection{Objekti radničkog stanovanja}

Objekti radničkog stanovanja su planski građeni objekti, odnosno, naselja čija je namena bila smeštaj radničkih porodica, a čiju su izgradnju finansirala velika kapitalistička preduzeća poput rudnika ili fabrika. Ovaj vid stanovanja je poznat pod nazivom radničke kolonije (Janjušević, 2015.).

Radničke kolonije predstavljaju poseban tip industrijskog nasleđa. One su građene u blizini rudnika ili industrijskih postrojenja. Najznačajnije radničke kolonije građene u 19. i prvoj polovini 20. veka postoje u Vrdniku (gde su građene za potrebe rudnika mrkog uglja), Beočinu (za potrebe fabrike cementa), Vrbasu, Odžacima (za potrebe Fabrike za preradu kudeljnog vlakna) i Zrenjaninu (u sklopu kompleksa šećerane). 
Prva radnička kolonija u Beočinu sagrađena je između 1855. i 1860. godine i nazvana je „Filijala“. Centralna radnička kolonija, koja se nalazi u neposrednoj blizini fabrike, sagrađena je u periodu od 1894. do 1914. i uz nju se formirao centar današnjeg grada sa pratećim objektima i administrativnom upravom. Treća radnička kolonija, u Donjem Šakotincu, osnovana je takođe u 19. stoleću, u dolini zapadno od fabrike cementa (Janjušević, 2015.).

\subsection{Hidrotehničko nasleđe}

Teritorija današnje Vojvodine obiluje raznovrsnim hidrološkim objektima. Prvi radovi na regulaciji voda zabeleženi su još za vreme Rimskog carstva u Sremu. Ozbiljniji melioracioni radovi započeli su sa uspostavljanjem Habsburške vladavine u 18. stoleću. Godine 1728. počinju radovi na iskopavanju Begejskog kanala, odnosno veštačkog korita Begeja dugog 70 kilometara, od Temišvara do Bečkereka (Đekić i Milić, 2016.).

Slika 5.

Hidrotehnički objekat crpne stanice kod Žablja iz 1898. godine

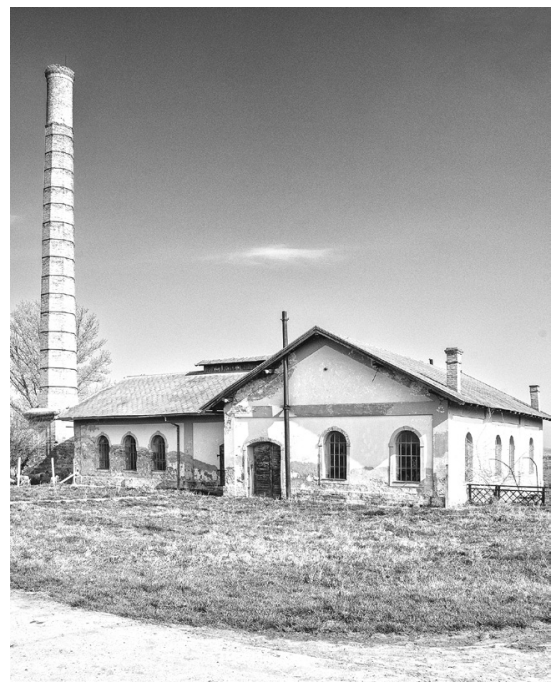

Foto: Lazar Lazic

Najobimniji melioracioni radovi izvedeni su na teritoriji Bačke. Započeti su krajem 18. stoleća, a nastavljeni tokom čitavog 19. stoleća. Prvi kanal je izgrađen između 1793. i 1802. godine po projektu Jožefa i Gabora Kiša i povezivao je Dunav i Tisu od Bačkog Monoštora do Bačkog Gradišta (Milošev, 2002.; Bakić, 2011.). Osim na mestima gde se kanal spajao sa Dunavom i Tisom, vodne stepenice sa prevodnicama postojale su i u Vrbasu, Malom Staparu i Srbobranu. Od prvobitno sagrađenih prevodnica danas je u funkciji samo ona u Malom Staparu (Đekić i Milić, 2016.), a takođe su još sačuvane prevodnice u Bezdanu (slika 1) i Bečeju. Kanalska mreža je građena radi isušivanja močvarnog zemljišta i njegovog privođenje poljoprivrednoj nameni, zbog 
navodnjavanja i brodskog saobraćaja (Petrović, 1978.; Gavrilović, 1972.). Ovom tipu objekata industrijskog nasleđa pripadaju i brojne crpne stanice za odvođenje visokih voda, od kojih su posebno značajne one u Žablju (slika 5) i Plavni.

\subsection{Objekti transportne infrastrukture}

Među objektima transportne infrastrukture, koji se mogu svrstati u industrijsko nasleđe Vojvodine, izdvajaju se objekti železničke infrastrukture (železničke stanice, ranŽirne stanice). Prvi voz na području današnje Vojvodine pojavljuje se 1854. u južnom Banatu, a 1857. puštena je u promet pruga Segedin - Velika Kikinda - Temišvar (Stanojev, 2002.). Početkom 20. stoleća, Vojvodina je imala najgušću železničku mrežu u Podunavlju što je doprinelo ekonomskom razvoju i omogućilo urbanizaciju i dalji razvoj industrijske proizvodnje.

Gustina železničke mreže uslovila je izgradnju velikog broja železničkih stanica i pratećih objekata. Najveći broj ovih zgrada rađen je po tipskim projektima, a njihova veličina je varirala od lokalnih potreba, odnosno veličine naselja i ranga železničkog čvora. Postojali su tipski projekti za stanične zgrade I, II i III klase. Železničke stanice su najčešće građene sa dve etaže, a objekti koji su podignuti početkom 20. veka pokazuju veću slobodu u arhitektonskom i likovnom oblikovanju, često pod uticajem tada aktuelnog secesijskog stila. Zgrade koje se posebno ističu slobodnijim konceptom su železnička stanica u Vršcu, izgrađena 1902. od klinker opeke, stanice u Horgošu i Naumovićevu (u stilu secesije) i u Novom Žedniku (u duhu arhitekture „Grupe mladih“ iz Budimpešte) (Prčić-Vujnović, 2016.).

Pored staničnih zgrada građene su i prateće zgrade, kao što su vodotornjevi (za potrebe hlađenja parnih lokomotiva), magacini, kružne okretnice i drugi objekti. Među objektima ove vrste posebno se ističu oni na železničkoj stanici u Bogojevu.

Tipologije industrijskog nasleđa i njihovo razvijanje, mogu biti i jesu važni koraci u boljem prepoznavanju objekata industrijskog nasleđa Vojvodine, sa svim odlikama i specifičnostima. S obzirom na to da je jedan od preduslova održivog korišćenja ovog segmenta baštine i poštovanje karaktera nekog objekta, onda razvrstavanje po tipovima može da pomogne u boljem razumevanju osobenosti konkretnih tipova i pojedinačnih objekata. Takav pristup je preduslov za razvijanje modela održivog korišćenja, koje mora biti usklađeno sa zaštitom i vrednostima objekata industrijskog nasleđa.

\section{Održivo korišćenje objekata industrijskog nasleđa u Vojvodini}

Tema održivog korišćenja industrijskog nasleđa je stara više decenija i u žižu interesovanja je došla sa procesom deindustrijalizacije, koja je društvima Zapadne Evrope poznata od šezdesetih godina 20. veka (Mackinnon i Cumbers, 2007.). To je mnoge industrijske regije nateralo na ekonomsko restrukturiranje koje treba posmatrati kao ključni segment ukupne transformacije ranijih industrijskih struktura u cilju oživljavanja ekonomske konkurentnosti i produktivnosti, uz održavanje ili jačanje zaposlenosti (Koutský et al, 2011.). 
Revitalizacija i novi vidovi korišćenja objekata industrijskog nasleđa nužno nameću potrebu podrobnijeg poznavanja istorije objekta ili industrijskih predela u gradovima. Industrijski predeli ili stari industrijski regioni, kako se još spominju u literaturi, odlikuju se sledećim osnovnim parametrima: (1) povećana gustina stanovništva; (2) natprosečno prisustvo industrijske infrastrukture; (2) rana pojava industrijalizacije u odnosu prema drugim delovima zemlje; (3) regionalna ekonomija koju odlikuje nadmoć konkretnog proizvodnog sektora; (4) preovladavanje velikih organizacija (ili jedne organizacije) i (5) mala sposobnost da se procesi transformacije sprovedu isključivo sa internim resursima (Hamm i Wienert, 1990.). Postavljanje ovih parametara u vezu sa razvojem industrijskih regiona ili pojedinih centara u Vojvodini, može se uočiti da njihov industrijski razvoj obeležavaju upravo navedene odlike. Gustina stanovništva je povećana u gradovima koji su zabeležili pojačan industrijski rast od 19. veka do danas. U mnogim gradovima i danas se jasno uočava povećano prisustvo industrijskih objekata, a u nekima od njih ovi objekti jasno doprinose oblikovanju fizionomije i ukupne vizure (npr. Pančevo, Zrenjanin, Novi Sad, Vrbas i drugi). Dominantna grana je industrija poljoprivrednih proizvoda, jasno potvrđujući da su industrijski objekti Vojvodine nastajali iz manufaktura i na osnovu akumulacije kapitala. Najzad, nakon Drugog svetskog rata u razvoju industrijskih predela i centara Vojvodine preovladavale su institucije velikih organizacija, sa naglašenom ulogom monopola.

Korišćenje industrijske baštine na način koji naglašava njen kulturni značaj široko je rasprostranjen. Ovo je važno za prostore koji su pretrpeli opadanje industrijske funkcije, naročito u saznanju značaja kulture za politike razvoja. Kultura se često vidi kao idealna zamena za napuštene industrijske objekte, kao instrument koji će kreirati novu privlačniju sliku grada (Cizler, 2016.). Jedan od najčešćih načina prenamene je preobraćanje objekata u muzej, mada su ovde prisutni i drugi vidovi novog korišćenja. Funkcionalno upotrebna vrednost kulturnog nasleđa prioritetna je za donošenje odluke o daljem postupanju prema nasleđenoj baštini. Rekonstrukcija i novi vidovi korišćenja objekata uključuju osmišljavanje i realizaciju sledećih sadržaja: (1) tematski muzej, (2) tematski park, (3) poslovno-zabavni centar; (4) art-centar (galerije i izložbeni saloni); (5) poslovno-stambeni objekti (Milanović et al, 2013.).

Trenutno je u Vojvodini najpoznatiji primer nekadašnje fabrike Petar Drapšin („Kineska četvrt") u Novom Sadu. Ovaj prostor je dugo bio zapušten, a delimično je to i danas. Ipak, u prethodnih deset godina ovde su se spontano koncentrisale kulturne i ugostiteljske ustanove, pa je „Kineska četvrt“ danas sedište četiri institucije kulture, tri slikarska i tri muzička ateljea, jednog pozorišta i dva objekta za organizovanje kulturnih i umetničkih dešavanja. Zbog pažnje koju izaziva i brojnih aktivnosti koje se ovde preduzimaju, kompleks bivše fabrike bi trebalo da postane novo kulturno središte grada do 2021. godine, kada će Novi Sad biti Evropska prestonica kulture. Ukoliko se to i dogodi, onda bi ovaj objekat mogao biti skoro jedini primer očuvanja industrijskog nasleđa u Vojvodini kroz uvođenje kreativnog distrikta i primer održive revitalizacije.

U teoriji i praksi turizam se često prepoznaje kao jedan od faktora u aktivnom i održivom korišćenju industrijskog nasleđa (Feifan Xie, 2015.). Veliko interesovanje 
za ovu oblast uticalo je i na veliki broj različitih pristupa u proučavanju turizma koji se bazira na industrijskom nasleđu. Prema jednom shvatanju industrijski turizam se definiše kao poseta mestima industrijske proizvodnje, koja su aktuelna i još uvek u funkciji, s ciljem upoznavanja procesa proizvodnje. To je iskustvo koje izaziva posebno oduševljenje nečim što je nezaboravno i autentično (Otgaar et al, 2010.). Turizam industrijskog nasleđa obuhvata turizam koji se bazira na poseti industrijskih objekata koji nisu više u funkciji. To je isključivo oblik turizma na onim industrijskim lokacijama na kojima je primarna funkcija prestala (Frew, 2000.). Postoji više oblika korišćenja industrijskog nasleđa u turizmu: (1) obilazak i razgledanje objekata; (2) edukativna prezentacija estetskih elemenata osobene industrijske arhitekture; (3) edukativna prezentacija radnog procesa i tamo gde je moguće demonstracija rada starih mašina; (4) prenamena objekata u rekreativne svrhe (sportski tereni, rekreacija, razonoda); (5) prenamena objekata u kulturne turističke centre, koji popularizuju kulturne sadržaje o industrijskom nasleđu ili nekom drugom segmentu nasleđa; (6) preuređenje u hotelske i ugostiteljske objekte.

Slika 6.

Prevodnica u Malom Staparu

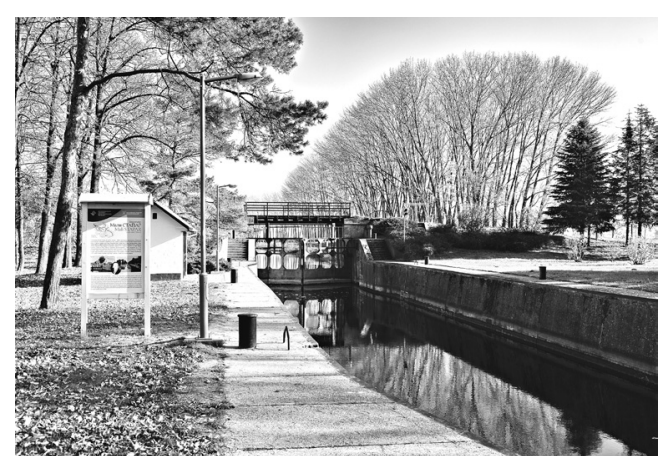

Foto: Lazar Lazić

Slika 7.

Nasleđe u Malom Staparu u funkciji planiranog turističkog lokaliteta - mlin (desno) i zgrada Tehničke direkcije kanala (levo)

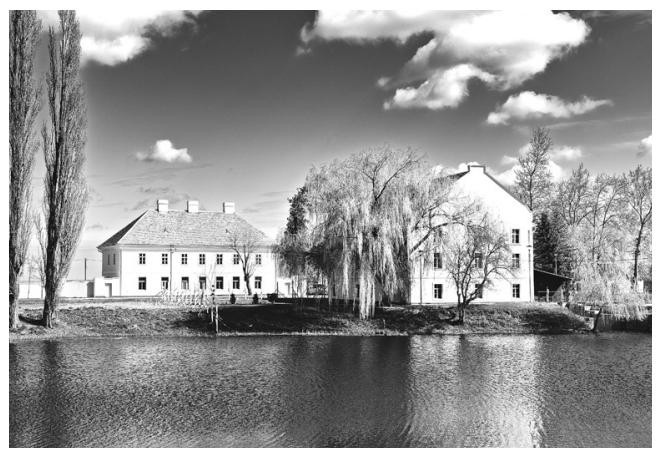


Ukoliko se izuzmu planovi razvoja i informacije na internet portalima, npr. turističke organizacije Pančeva i Odžaka, za sada u turizmu Vojvodine nije prisutna turistička prezentacija industrijske baštine. Put ka održivom razvoju turizma, zasnovanom na industrijskoj baštini, zaustavlja se na planovima. Konkretan primer je i Strategija razvoja turizma u opštini Odžaci (2007.), koja prepoznaje „turizam industrijskog nasleđa“ kao jedan od prioritetnih turističkih proizvoda, s ciljem pokretanja turističkih sadržaja u nekadašnjoj Fabrici kanapa i užarije. Nažalost, tada identifikovani nedostaci, kao što su nedovoljno razvijena svest o novoj nameni, propadanje objekta i odsustvo zaštite, nikada nisu otklonjeni. Prvobitnu ideju turističkog preuređenja ometa i nedostatak preduzetničkog duha. Dokument Prezentacija, promocija i aktiviranje prirodnih i kulturnih sadržaja Malog Stapara (2010.), kompleksa objekata industrijskog nasleđa (slika 6), predviđa prenamenu objekata industrijskog nasleđa u turističke kapacitete i sadržaje (muzeji, sadržaji animacije, ugostiteljski kapaciteti). Ovaj primer je drugačiji od prethodnog utoliko što je objekat u konzervatorskom smislu prilično rekonstruisan (slika 7), ali bez funkcije novog korišćenja u turističke svrhe, zbog odsustva inicijative.

\section{Zaključak}

S obzirom na postavljena istraživačka pitanja, a u vezi sa zaštitom, tipologijom i održivim korišćenjem, jedan od ciljeva ovog rada je da obrazloži važnost, sadržajnost i složenost industrijskog nasleđa Vojvodine. Osnovni cilj je se da ukaže na neophodnost zaštite ovog segmenta baštine, jer se time ne čuvaju samo graditeljski objekti, već se podstiče i očuvanje identiteta i društveno-ekonomski razvoj (održivo korišćenje). Nažalost, dosadašnja praksa uglavnom upućuje tek na sporadične primere planiranja takvog korišćenja.

Vojvodina ima dugu tradiciju razvoja industrije i shodno tome veliki broj industrijskih objekata, predela i značajno nematerijalno nasleđe, što je posledica njene industrijske prošlosti. Zakonodavstvo u Srbiji ne prepoznaje takve objekte kao posebnu vrstu kulturnog dobra, već se oni mogu zakonski štititi kao neka od postojećih kategorija kulturnih dobara na osnovu nadležnog Zakona.

Razvijanje tipologija, kao sastavni deo procesa inventarizacije industrijskog nasleđa, trebalo bi da pomogne boljem prepoznavanju ovakvih objekata na terenu. Skretanje pažnje javnosti na vrednost industrijskog nasleđa i mogućnosti korišćenja njegovih potencijala za dobrobit zajednice, jedan je od početnih koraka u revitalizaciji ove vrste baštine. Lokalne samouprave, specijalizovane ustanove, kao i javne ličnosti imaju mogućnost da zanemarene oblike nasleđa prezentuju široj publici putem publikacija, izložbi, televizijskih emisija, interneta i drugih vrsta medija. Na taj način bi se podstaklo interesovanje za održive investicije u ove objekte i njihovo promovisanje u cilju razvoja turističke ponude, kao dobrog načina održivog korišćenja industrijskog nasleđa.

Revitalizacija kroz održivo korišćenje objekata industrijskog nasleđa može se posmatrati i u svetlu razvoja kulture ili turizma. Tek sporadični primeri u Vojvodini svedoče 
o tome, poput napuštene fabrike Petar Drapšin u Novom Sadu, koja je na putu da postane kulturni distrikt. Razvoj turizma u objektima industrijskog nasleđa ima tek uporište u lokalnim planovima, ali ne i u njihovoj realizaciji, što je samo još jedan od dokaza kompleksnosti praktične primene ideja revitalizacije ovog segmenta kulturne baštine.

\section{Literatura}

1. Adams, B. (2009). Sustainable development, in: Gregory, D.; Johnston, R. J.; Pratt, G.; Watts, M.; Whatmore, S. (Eds.). In The Dictionary of Human Geography. Chichester. John Wiley \& Sons Ltd: 739-739.

2. Bakić, S. (2011). Stara brodska prevodnica kod Bečeja (istraživanja i projekat obnove). Građa za proučavanje spomenika kulture Vojvodine, XXIV-XXV: 7-23.

3. Becher, B. i H. (2004). Typologies of Industrial Buildings. Cambridge, Mass. MIT Press.

4. Cizler, J. (2012). Urban regeneration effects on industrial heritage and local community - Case study: Leeds, UK. Sociologija i prostor, 50 (2): 223-236.

5. Cizler, J. (2016). Aktiviranje napuštenih industrijskih objekata u gradovima: institucionlna ograničenja u Srbiji. Doktorska disertacija u rukopisu. Beograd: Arhitektonski fakultet, Univerzitet u Beogradu.

6. Đekić, M. i Milić, B. (2016). Hidrotebničko nasleđe, industrijsko i tebničko nasleđe $u$ Vojvodini. Zrenjanin: Zavod za zaštitu spomenika kulture Zrenjanin, 7-21.

7. Falser, M. (2001). Is Industrial Heritage under-represented on the World Heritage List?. Industrial Heritage Analysis, Global Strategy Studies. http://whc.unesco. org/archive/ind-study01.pdf. (Pregledano 18.10.2016.)

8. Feifan Xie, P. (2015). Industrial Heritage Tourism. Bristol, Buffalo, Toronto: Channel View Publications.

9. Fetisov, O. (2013). Analysis of the Modern Typology and Classification of Industrial Architecture in European Urbanized Cities. CESB13 Prague. Industrial heritage regeneration.

10. Frew, Elspeth A. (2000). Industrial tourism: A conceptual and empirical analysis. Unpublished PhD dissertation, Victoria University of Technology.

11. Gavrilović, S. (1972). Plovidba na kanalima DTD. Novi Sad: Hidrosistem DTD.

12. Gorjup-Kavčič, M.; Režun, B.; Eržen, U.; Peljhan, M.; Mulec, I. (2010). Natural, Cultural and Industrial Heritage as a Basis for Sustainable Regional Development within the Geopark Idrija Project (Slovenia). Novi Sad: Geographica Pannonica, Department of Geography, Tourism and Hotel Management, Faculty of Science, 138-146.

13. Hamm, R. i Wienert, H, (1990). Strukturelle Anpassung altindustrieller Regionen im internationalen Vergleich. Berlin: Duncker \& Humbolt.

14. Hudson, K. (1963). Industrial Archaeology: An Introduction. London: John Baker.

15. Industrial Heritage in Europe, 2013. http://assembly.coe.int/nw/xml/XRef/XrefXML2HTML-en.asp?fileid=19493\&lang=en. (Pregledano 21.01.2018.) 
16. Janjušević, B. (2015). Industrijsko nasleđe Beočina - istraživanje i mogućnosti revitalizacije. International conference: Heritage in Context of New creative Spaces for Cultural and Economic Development. Novi Sad.

17. Johnson, N. (2009). Heritage, in: Gregory, D.; Johnston, R. J.; Pratt, G.; Watts, M.; Whatmore, S. (Eds.). In The Dictionary of Human Geography. Chichester: John Wiley \& Sons Ltd, 327-328.

18. Joint ICOMOS - TICCIH Principles for the Conservation of Industrial Heritage Sites, Structures, Areas and Landscapes - The Dublin Principles, 2011. https:// www.icomos.org/Paris2011/GA2011 ICOMOS TICCIH joint principles EN FR final 20120110.pdf. (Pregledano 10.05.2017.)

19. Karavida, V. (2014). Gradska klanica arbitekte Sekelji Lasla u Zrenjaninu, Građa za proučavanje spomenika kulture Vojvodine 20. Petrovaradin: Pokrajinski zavod za zaštitu spomenika kulture, 65-73.

20. Karavida, V. (2016a). „Industrijska arbitektura Zrenjanina“. Beograd: Glasnik Društva konzervatora Srbije 37, 157-161.

21. Karavida, V. (2016b). „Industrijska proizvodnja prehrambena industrija“. Zrenjanin: Zavod za zaštitu spomenika kulture Zrenjanin, 22-37.

22. Kicošev, S.; Bubalo-Živković, M. i Ivkov, A. (2006). Stanovništvo Bačke. Novi Sad: Departman za geografiju, turizam i hotelijerstvo; Prirodno-matematički fakultet.

23. Koutský, J.; Slach O. and Tomáš B. (2011). Restructuring Economies of Old Industrial Regions - Local Tradition, Global trends. In The Scale of Globalization. Think Globally, Act Locally, Change Individually in the 21st Century. Ostrava: University of Ostrava, 166-173.

24. Lee, R. (2001). Deindustrialization, in: Johnston, R. J.; Gregory, D.; Pratt, G.; Watts, M. (Eds.). In The Dictionary of Human Geography. Oxford: Blackwell: $158-158$

25. Loures, L. (2008). Industrial heritage: The past in the future of the city. WSEAS Transactions on Environment and Development, 4: 687-696.

26. Mackinnon, D and Cumbers, A. (2007). An Introduction to Economic Geography - Globalization, Uneven Development and Place. Pearson, Prentice Hall, Harlow.

27. Mezei, S. (1959). Razvoj industrije u Bačkoj. Novi Sad: Istorijski arhiv PK SKS za Vojvodinu.

28. Mihajlov, V. (2009). Socijalni motivi i efekti regeneracije industrijskog nasleca. Sociologija i prostor, 47 (2): 139-164.

29. Milanović, Đ.; Radanović, M.; Milosavljević, I.; Milanović, J.; Rudnik Milanović, A.; Jurišić, M. (2013). Industrijsko nasleđe - zaštita i revitalizacija. Kragujevac: Zavod za zaštitu spomenika kulture Kragujevac.

30. Milošev, Ž. (2002). Hidrotehnički radovi u Banatu i Bačkoj pre izgradnje Hidrosistema Dunav-Tisa-Dunav. Hidrosistem Dunav-Tisa-Dunav - 25 godina posle. Novi Sad: Javno vodoprivredno preduzeće Vode Vojvodine.

31. Mirnić, J. (1963). Radnički pokret u Bačkoj. Novi Sad: Istorijski arhiv Pokrajinskog komiteta Saveza komunista Srbije za Vojvodinu.

32. Otgaar, A.; Berg, L.; Berger C.; Xiang Feng., R. (2010). Industrial Tourism: Opportunities for City and Enterprise. Aldershot: Ashgate.

33. Petrović, N. (1978). Plovidba i privreda srednjeg Podunavlja u doba merkantilizma. Beograd. 
34. Prčić-Vujnović, G. (2016). Graditeljsko železničko nasleđe, Industrijsko i tebničko nasleđe $u$ Vojvodini. Zrenjanin: Zavod za zaštitu spomenika kulture Zrenjanin, 53-67.

35. Prezentacija, promocija $i$ aktiviranje prirodnib $i$ kulturnih sadržaja Malog Stapara (2010). Novi Sad: Departman za geografiju, turizam i hotelijerstvo, Prirodno-matematički fakultet.

36. Recommendation No. R (90) 20. of the Committee of Ministers to member state on the protection and conservation of the Industrial, technical and civil engineering heritage in Europe, Council of Europe, 1990. http://www.culturanorte.pt/fotos/ editor2/1990-recomendacao_relativa_a_protecao_e_conservacao_do_patrimonio tecnico industrial e das obras de arte na europa-conselho da europa. pdf. (Pregledano 10.05.2017.)

37. Službeni glasnik RS, br. 71/94, Zakon o kulturnim dobrima.

38. Smith, D. (2001). Industrialization, in: Johnston, R. J.; Gregory, D.; Pratt, G.; Watts, M. (Eds). In The Dictionary of Human Geography. Oxford: Blackwell, 388-389.

39. Stanojev, T. B. (2002). Prva železnička pruga u Vojvodini, Zbornik radova Pruge i vozovi u Vojvodini. Pruge i vozovi u Vojvodini, PCESA. Novi Sad: Kulturnoistorijsko društvo Proleće na čenejskim salašima.

40. Stojanović, V. (2007). Razvoj morfoloških karakteristika Odžaka od XVIII do XXI veka. Novi Sad: Departman za geografiju, turizam i hotelijerstvo, Prirodnomatematički fakultet.

41. Strategija razvoja turizma opštine Odžaci (2007). Novi Sad: Departman za geografiju, turizam i hotelijerstvo, Prirodno-matematički fakultet.

42. Sýkora, M.; Holický M. and Marková, J. (2010). Advanced assessment of industrial heritage buildings for sustainable development cities development. Prague: CESB 10 Prague Conference.

43. The Nizhny Tagil Charter for the Industrial Heritage, The International Committee for the Conservation of the Industrial Heritage: Nizhny Tagil, 2003.

44. Tufegdžić, A. (2014). Tri veka vojvođanskih pivara: kontekst i kontinuitet. Doktorska disertacija u rukopisu.

45. Vrbaški, Đ. (2009). Pregled rada i razvoja Fabrike šećera „Bačka“ Vrbas 19132007. Vrbas.

46. Vujović, J. (2016). Prerađivačka industrija, Industrijsko i tebničko nasleđe u Vojvodini. Zrenjanin: Zavod za zaštitu spomenika kulture Zrenjanin, 38-51.

\section{Zahvalnica}

Ovo istraživanje je podržao Pokrajinski sekretarijat za visoko obrazovanje i naučnoistraživačku delatnost (Autonomna Pokrajina Vojvodina), projekat „Geotransformacija prostora Vojvodine u službi regionalnog razvoja“ 142-451-25811/2017-04. 
Pregledni rad

Vladimir Stojanović

University of Novi Sad, Faculty of Natural Sciences and Mathematics, Department of Geography, Tourism and Hotel Management, Serbia

e-mail:vladimir.stojanovic@dgt.uns.ac.rs

Bogdan Janjušević

Petrovaradin Province Institute for the Protection of Cultural Monuments, Serbia

e-mail: bogdan.janjusevic@pzzzsk.rs

\title{
Industrial Heritage in Vojvodina Today: Typology, Protection and Revitalization
}

\begin{abstract}
In the past few decades, issues related to industrial heritage have often been discussed at academic and practitioners' forums. Topics on industrial heritage are broad and range from identification, protection and revitalization to the sustainable use of industrial heritage. Because of the province's rich industrial past, the study of industrial heritage in Vojvodina is important both in Serbia and beyond its borders. This paper presents a brief historical overview of industrial development in the province of Vojvodina, followed by typological examples of industrial heritage and discussion about industrial and cultural heritage protection. The most effective way to protect industrial heritage structures today is their sustainable re-use since these buildings have lost their primary function and new forms of improper use threaten to wipe out all important evidence of industrialization in Vojvodina.
\end{abstract}

Key words: industrial heritage, deindustrialization, Vojvodina, typology, protection, revitalization, sustainable development. 